\title{
An Evaluation of the Feasibility of Implementing a Novel Tobacco Dependence Treatment Program for High-risk Individuals Into Clinical Practice Within a Community Mental Health Center
}

\section{Tory Hogan}

The Ohio State University

Amanda Quisenberry ( $\sim$ amanda.quisenberry@roswellpark.org)

Roswell Park Cancer Institute: Roswell Park Comprehensive Cancer Center

Nicholas Breitborde

The Ohio State University

Aubrey Moe

The Ohio State University

Amy Ferketich

The Ohio State University

\section{Research}

Keywords: evaluation of the feasibility, novel tobacco, clinical practice, community mental health center, high-risk

Posted Date: May 13th, 2021

DOI: https://doi.org/10.21203/rs.3.rs-515530/v1

License: (c) (i) This work is licensed under a Creative Commons Attribution 4.0 International License. Read Full License

Version of Record: A version of this preprint was published at International Journal of Mental Health Systems on February 20th, 2022. See the published version at https://doi.org/10.1186/s13033-02200517-y. 
An evaluation of the feasibility of implementing a novel tobacco dependence treatment program for high-risk individuals into clinical practice within a community mental health center

Authors:

Tory H. Hogan ${ }^{1}$, Amanda Quisenberry ${ }^{2}$, Nicholas Breitborde ${ }^{3}$, Aubrey Moe ${ }^{4}$, Amy Ferketich ${ }^{5}$

1. Tory H. Hogan, $\mathrm{PhD}$

Assistant Professor

College of Public Health

Division of Health Services and Policy

The Ohio State University

1841 Neil Ave

Columbus, $\mathrm{OH} 43210$

Email: Hogan.323@osu.edu

2. Amanda Quisenberry, $\mathrm{PhD}^{*}$

Assistant Professor

Department of Health Behavior

Division of Population Sciences

Roswell Park Comprehensive Cancer Center

Carlton House A-408

665 Elm Street

Buffalo, NY 14203

Email: Amanda.Quisenberry@RoswellPark.org

3. Nicholas Breitborde, $\mathrm{PhD}$,

Psychologist

College of Medicine

Department of Psychiatry and Behavioral Health

The Ohio State University

Email: Nicholas.breitborde@,osumc.edu

4. Aubrey Moe, PhD, MA

Psychologist

College of Medicine

Department of Psychiatry and Behavioral Health

The Ohio State University

Email: Aubrey.moe@osumc.edu

5. Amy Ferketich, PhD, MA, MAS

Professor

College of Public Health

Division of Epidemiology

The Ohio State University

1841 Neil Ave

Columbus, OH 43210

Email: Ferketich.1@osu.edu 
*corresponding author

\begin{abstract}
Background: Individuals with serious mental illnesses experience deaths related to smoking at a higher prevalence than individuals without a serious mental illness. Traditional smoking cessation programs are often not effective among individuals with chronic mental disorders. Little is known about how to implement a tobacco cessation treatment programs for this at-risk population within a community health centers. The current study used qualitative methods to examine the factors that may enhance or impede the delivery of a novel tobacco cessation treatment for smokers with a psychotic-spectrum disorder diagnosis in an integrated care community health center.

Methods: Using purposeful sampling, we conducted 22 semi-structured interviews with primary care providers, mental health providers, addiction counselors, case managers, intake specialists, schedulers, pharmacists, and administrative staff at employed at the organization. Interviews were transcribed and themes were identified through a rich coding process.

Results: We identified environmental factors, organizational factors, provider factors and patient factors which describe the potential factors which may enhance or impede the implementation of a smoking cessation program at the integrated care community health center. Most notably we identified that community mental health centers looking to implement a smoking cessation program for individuals with chronic mental health disorders should ensure that the incentives for providers to participate align with the program's objectives. Lastly, organizations should invest in educating providers to address stigma related to smoking cessation and nicotine use. Conclusions: The findings of our study provide valuable insight for administrators to consider when implementing a smoking cessation program in an integrated care community health center. Our findings provide public health practitioners with potential considerations that should be discussed when designing and implementing a smoking cessation program for individuals with chronic mental disorders.
\end{abstract}




\section{INTRODUCTION}

Compared to the general population, individuals with serious mental illnesses, such as schizophrenia, die approximately 20 years earlier ${ }^{1}$, with an estimated $53 \%$ of these deaths due to smoking $^{2}$. About two-thirds of individuals with schizophrenia smoke and less than $10 \%$ of ever smokers with serious mental illness have quit ${ }^{3-5}$, compared to almost $55 \%$ of ever smokers in the general population ${ }^{6}$. Community health center administrators and clinicians have very little guidance regarding smoking cessation programs which can effectively treat this population, and additionally how to implement such programs within a complex delivery setting such as a community health center. Public health experts estimate that smoking continues to be one of the major public health crisis in the U.S. Community health centers, which provide healthcare services to those who are uninsured and uninsured and often serve the most vulnerable communities need guidance to implement new and novel smoking cessation programs which aim to curb tobacco use among such vulnerable populations within our public health system.

Because individuals with chronic disabling mental disorders likely smoke, in part, due to the positive effects of nicotine on cognitive function ${ }^{7-9}$, traditional cessation programs are not effective in these smokers ${ }^{10}$. Thus, new programs are needed to help smokers with these serious mental illnesses quit. To this end, we developed a 12-week combination therapy that included traditional pharmacological treatment (i.e., bupropion, varenicline, or nicotine replacement therapy) and metacognitive remediation to quit (MCR-Q) therapy, an intervention that includes clinician-delivered metacognitive skill development exercises that are mastered via practice using computerized exercises ${ }^{11,12}$, for smokers with schizophrenia, schizophreniform disorder, schizoaffective disorder, or bipolar disorder with psychotic symptoms. MCR-Q, which is adapted from Metacognitive Remediation Therapy $\left(\mathrm{MCR}^{13,14}\right)$ for individuals with psychosis, is designed 
to develop skills and strategies to address specific real-world situations related to quitting smoking.

In order for an effective smoking cessation program to have an impact, it must be easily incorporated into clinical practice. Barriers and facilitators to implementing tobacco treatment in mental health and substance use treatment programs have been reported ${ }^{15-19}$; however, most of these investigations have occurred in substance abuse treatment centers ${ }^{15,16}$. Little is known about the feasibility of implementing a tobacco dependence treatment program into integrated community health centers, which focus simultaneously on treatment of mental health, chemical dependency, and primary care, as well as provide employment and homelessness services. In addition, Community health centers receive funding from multiple agencies and state and federal programing, making the management of such organizations complex. The little information that is available comes from facilities that specifically treat veterans ${ }^{17,19}$, who are a special population in their own right and have a unique service billing structure through the Department of Veteran's Affairs.

Our public health system relies significantly on community health centers to provide primary care and mental health services to some of the most vulnerable populations in our society. More research exploring the implementation and feasibility of clinical care programs on our vulnerable populations will provide managers and administrators with guidance to facilitate the appropriate treatments for their clients. The current study employed qualitative methods to examine the factors that may enhance or impede the delivery of our combination tobacco cessation treatment for smokers with a psychotic disorder diagnosis in an integrated care community health center. The findings provide valuable insight for managers and administrators regarding the implementation of a smoking cessation program in an integrated care community health center. 


\section{METHODS}

\section{Setting}

The MCR-Q intervention was implemented at a community healthcare organization in Ohio. This particular organization was selected, in part, because it is a comprehensive provider of mental health, addiction treatment, and primary care services. This organization employs a wide variety of care providers such as physicians, nurse practitioners, licensed social workers, case managers, psychiatrists, and clinical psychologists who work inter-professionally to serve the needs of their community across facilities in four counties. Moreover, this organization provides a wide range of mental health, primary care, employment, and homelessness services to over 8,000 adults who have a range of mental health disorders, including over 1,000 with one of the psychotic-spectrum disorder diagnoses we targeted in our smoking cessation program. In addition to serving the behavioral health needs of individuals with mental illness, the health center provides primary health care, dental care, substance use treatment, housing, employment services, and several other special programs to serve this vulnerable population. Thus, it is truly an integrated physical and behavioral health setting built on the patient-centered medical home model $^{20}$. The primary care services are provided at the organization's Federally Qualified Health Center (FQHC).

The foundation of the smoking cessation program is MCR but it was tailored to promote quitting smoking (MCR-Q). Across the 12-session intervention, individuals participate in therapist-delivered metacognitive skills development exercises designed to facilitate improved knowledge and regulation of skills applied during completion of activities requiring the use of working memory, sustained attention, and behavioral disinhibition - three cognitive domains

repeatedly linked to tobacco use ${ }^{21}$. These skills are practiced in-session using computerized 
training exercises (Bracy, 2012) that require the use of these three cognitive skills to facilitate mastery. Withing-session conversations linking these skills to specific aspects of smoking cessation are included in each session to facilitate application of these skills within participants real-world smoking cessation activities. Consistent with clinical guidelines for smoking cessations $^{22}$, these psychotherapeutic activities are complimented with concurrent participation in smoking cessation pharmacotherapy in the form of bupropion, varenicline, or nicotine replacement therapy.

\section{Interview procedures}

The current interview sub-study was approved by the Institutional Review Board of the Ohio Department of Health. Interviews were conducted by TH using a face-to-face format at the organization's office where the cessation program was offered. Informed consent was obtained prior to participation, and each participant received $\$ 20$ for their participation in the study. To minimize the burden on participants, interviews lasted approximately 30 minutes and participants received a \$20 gift card. We developed a semi-structured interview guide that assessed perceptions of barriers and facilitators of implementing the program within the organization. Interviews were digitally recorded and then transcribed by three undergraduate students.

\section{Participants and recruitment}

Using purposeful sampling ${ }^{23}$, we interviewed primary care providers, mental health providers, addiction counselors, case managers, intake specialists, schedulers, pharmacists, and administrative staff at the organization. Potential interviewees were identified with the help of the therapy team leadership and the organization's leadership. The research team communicated 
the goals and objective of the study to the organization's leadership team. The leadership team sent an initial recruitment e-mail to all staff using their internal e-mail system. We conducted interviews prior to the start of the MCR-Q program and recruited individuals who worked in roles within the organizational related to smoking cessation (e.g., nurses, physicians) or worked with clients who may utilize smoking cessation services (e.g., case managers, counselors). Questions related to the program were asked, including: resources available, barriers, financial impact, training of staff, and staff attitudes towards a new program. Prior to the start of the interview, participants were

A total of 22 interviews were conducted and were deemed appropriate because the study had reached saturation ${ }^{24}$. The final interview sample included 3 case managers, 2 nurse practitioners, 2 therapists, 2 team leaders, 2 residential specialists, 2 cognitive enhancement therapy workers, 1 pharmacist, 1 primary care physician, 1 residential program manager, 1 intake coordinator, 1 receptionist, 1 assistant clinical director, 1 clerk, 1 recovery guide, and 1 social worker. We anticipated further sampling after our initial coding, however the interviews were consistent and similar in themes and we believe additional interviews would not have yielded additional insights. This study was approved by the state of Ohio IRB, study ID 2017 X0036.

\section{Analyses}

Prior to analyzing the data, two student researchers transcribed each interview using a protocol developed by the first author. One researcher transcribed each interview, including the questions and responses, and another checked the work and made edits to the transcript where needed.

As suggested by Creswell ${ }^{24}$, the analysis proceeded through the following steps: 1 ) preliminary examination of the data where the primary author reviewed the transcribed 
interviews and took notes; 2) coding each interview within each case; 3 ) using the codes to develop themes and sub-themes; 4) verifying the themes and sub-themes with other members of the research team; 5) connecting and inter-relating themes; and 6) constructing a case study table consisting of themes, sub-themes, and illustrative quotes for each case. The data verification process included member checking by confirming the interviewer's understanding of the interviewee's response by summarizing and paraphrasing throughout the interview ${ }^{25}$, crafting $^{2}$ rich descriptions of the interviews, and confirming information from the interviews with MCR-Q team members.

\section{RESULTS}

Through our analyses, we identified 4 levels of factors, which included 8 themes. Table 1 contains the levels of factors and themes that emerged from the interviews, along with illustrative quotes. In the next few sections we describe our assessment of the issues that are important to consider and understand when implementing the MCR-Q program into clinical practice.

\section{Environmental Level Factors}

These factors are contextual and associated with the broader regulatory and policy system that are critical to understand when considering the implementation of the MCR-Q program. Among this factor level, we identified one theme: reimbursement mechanisms. This was described by participants as a potential facilitator or barrier to implementing the MCR-Q program. This theme describes how the organization's ability to implement a program will be based on whether or not they can receive reimbursement for MCR-Q. As an FQHC, the organization relies primarily on Medicaid and Health Resources and Services Administration (HRSA) funding mechanisms which have specific billing requirements. At the time of the 
interviews, the research team was able to confirm that the activities of the program would meet the requirements of the smoking cessation programs for these reimbursement mechanisms. HRSA provides funding for the primary care center within the comprehensive care clinic. Medicaid reimburses for the addiction and behavioral health services offered at the comprehensive care clinic. When evaluating the feasibility of the MCR-Q program, the ability to be reimbursed is a significant consideration which would impact the ability to effectively implement this program.

\section{Organizational Level Factors}

Participants described several issues related to how the organization operates that are important to consider when evaluating the feasibility of the MCR-Q program.

The first theme, aligning the human resource incentive program with $M C R-Q$, describes how the organization utilizes productivity hours as the basis for salary and compensation for a large number of its employees. This was the second most frequently discussed sub-theme of the study. Employees are required to keep track of productivity hours related to their time spent with clients providing services. For example, when a therapist spends one hour leading a group therapy session, they receive one productivity hour. Each staff member has a goal for monthly productivity hours and upon meeting each monthly goal they receive additional compensation. Every participant discussed how they would need to be able to receive productivity hours for their efforts related to the MCR-Q therapy program in order for the program to be successful at their organization.

The second theme, multi-disciplinary provider teams, describes how the organization has multi-disciplinary teams which are comprised of primary care, mental health, and addiction 
services providers which is amenable to the MCR-Q program and the clinicians needed to implement such a program. The MCR-Q program specifically utilizes a multi-disciplinary team of an MD or Nurse Practitioner (NP), a therapist, and potentially a case worker. Our findings suggest that our organization had the multi-disciplinary teams already in place, which would be necessary to implement the program. Thus, the new program would not require any new hiring. Provider level factors

Participants described several issues that would impact the implementation of a new smoking cessation program, which were factors pertaining care providers within the organization.

The first theme, buy-in/attitudes of providers and team members, describes the role of the provider and other team members' buy-in or attitude towards smoking cessation and how that would impact implementation of MCR-Q. The clinic involved in this study utilizes interprofessional teams made up of social workers, primary care providers (MDs and NPs), pharmacists, psychiatrists, case managers, counselors, and social workers. Each person is responsible for various components of a client's care. The new MCR-Q program has the potential to impact how some of these individuals provide care, for example, the psychiatrist may need to adjust medications or be aware that a client could be more irritable while trying to quit smoking. Our findings suggest that clinicians often lack time and may prioritize other patient health issues over smoking cessation.

The second theme, provider prescribing behaviors, describes how the new smoking cessation program would require providers to potentially alter their medication treatment plans. Participants described how a vital part of the program being successful will fall on the willingness and ability of prescribing providers to adjust medications if necessary due to a person 
quitting smoking, taking cessation pharmacotherapy, or experiencing an adverse event to a cessation medication ${ }^{26}$. This theme addresses the role of provider buy-in within the context of a client's care and treatment. Some participants also explained that providers may not be willing to prescribe medications that they do not usually include in a regimen.

The third theme, workload constraints, describes how providers within the organization stated that a barrier to successful implementation of the smoking cessation program was a lack of time within the workload of the providers caring for clients. Multiple interviewees stated that this would be "one more thing" for them to do, within a long list of job tasks. Participants described being open to the treatment, since quitting smoking was an important thing for their patients, but also expressed difficulty in understanding how they would be able to continue to do what they are already doing while adding another task to their list of responsibilities.

\section{Patient level factors}

Patient factors describe two issues that would impact the implementation of a new smoking cessation program, which pertained to a person's willingness to participate in the program.

The first theme, competing patient needs and priorities, describes a common theme identified during our analyses which is related to the competing priorities for the individuals seeking smoking cessation treatment. Study participants expressed that due to the complex health and social needs of the clients, it may not be feasible to address smoking cessation during interactions. Many of the clients who receive care at this organization deal with homelessness, food insecurity, have other addition issues which are considered higher priority, and may have a co-diagnosis that creates complex needs. Due to these issues, participants expressed that smoking cessation may not be the issue that takes priority. Two participants referenced the "Maslow's 
hierarchy of needs" with regard to the program and expressed that individuals with serious mental illness often put quitting smoking low on their hierarchy of needs.

The second theme, motivation to quit smoking, describes one barrier to implementing MCR-Q is that smokers may not be interested in quitting smoking. Within this theme participants described how recruiting smokers and getting them to adhere to the program will require someone to convince clients that quitting smoking is something they should do. This theme specifically describes the need to address the buy in and attitudes of patients.

\section{DISCUSSION}

This study is responsive to critical gaps in the implementation of smoking cessation for people with mental health disorders that include psychotic symptoms - the need for an effective smoking cessation program and the need for evidence to support the implementation of such programs within integrated community health centers. Translating what is learned into research into real world settings is far more complex and challenging than it appears ${ }^{27}$. Integrated community health centers face limited financial and human resources, making it difficult to have the bandwidth needed to change clinical care practices and implement new care practices ${ }^{28}$. Our findings identify key factors to consider when planning to adopt the MCR-Q program in an integrated community health center. We identified environmental, organizational, provider, and patient level factors, which provide insight for leaders planning on implementing the MCR-Q program. Our findings are consistent with implementation science studies which have found that patients, providers, organizations, and the payer environment play a vital role when implementing a new evidence-based practice into care ${ }^{29}$. 
Our study found that staff perceive reimbursement mechanisms as being an important factor to consider when evaluating the feasibility of implementing a MCR-Q program. Federal and state policy makers determine HRSA and state Medicaid reimbursement policies which are responsible for determining the services within the MCR-Q program that community mental health centers could bill for. It is common for community mental health centers to rely on two major revenue sources: HRSA reimbursement for the organization's FQHC activities and Medicaid for mental health and substance abuse services. The MCQ-R program would require a primary care clinician, psychiatrist or mental health nurse practitioner to prescribe cessation pharmacotherapy, provide medication management, and trouble shoot with patients who may need medication adjustments as a result of either quitting smoking or side effects of the cessation pharmacotherapy. This finding suggests that integrated community health clinics have a strong need for any smoking cessation programs to work within the already existing reimbursement mechanisms. This would be a key consideration for all organization's considering the MCQ-R program.

Next, we identified two themes which we considered to describe organizational level factors which describe issues that should be evaluated as part of understanding the feasibility of the MCR-Q- program. The bulk of smoking cessation programs are implemented at primary care, substance abuse treatment centers, and mental health clinics. Our study was the first to examine the feasibility of implementing a combination smoking cessation therapy in a comprehensive community care clinic which offers integrated mental health, substance abuse treatment, and primary care under a single organizational entity. We found that staff at our organization believed that their organization's multidisciplinary approach to patient care was an 
added benefit and made their organization a good fit for the MCR-Q program, which incorporates pharmacological with behavioral health interventions into a single treatment.

We also found that staff experience or perceive a struggle to get buy-in from providers, while other employees perceive providers to be very supportive. These findings are consistent with previous studies which have identified a multitude of barriers to the provision of smoking cessation program among clinicians working with underserved communities ${ }^{30}$. During our interviews, it was suggested that if the integrated behavioral health center was going to implement such a program, there needed to be a focus on training staff and providers on benefits of the MCR-Q treatment they were referring patients to. This may help improve buy-in from providers who were able to understand how such a treatment may benefit their clients in a more effective way. Further studies looking to implement a MCQ-R program should strongly consider establishing a training mechanism for individuals within the organization to ensure that all individuals along the care continuum are able to understand the benefits of the MCR-Q treatment. This could also ensure that patients are appropriately referred to the program. Coupled with this finding, our study identified competing patient social needs and priorities as a common theme. This finding is consistent with previous research which has identified that patients with multiple co-morbidities may struggle to prioritize smoking cessation. Interviewees reported that the competing priorities of their patients might make it especially challenging when implementing a smoking cessation program. Employees working with clients are managing a wide array of patient needs, which can include housing, food, medication assistance, and complex co-morbidity disease management. Previous research has found that few mental health providers ask patients about smoking and smoking cessation readiness ${ }^{31}$. It is unclear if our findings are a result of a lack of readiness exhibited by the client, or if this result is based on 
cultural aspects of the individual's interviews. It is also not clear if more resources for the provider would mediate this issue and potentially enable the provider to have more time with the patient, which could be used to address smoking cessation.

\section{LIMITATIONS}

Limitations of the study include conducting interviews with staff at one integrated care community care clinic and, thus, results may not be generalizable. In addition, participants were all employed by the community mental health clinic, which may bias their responses to the interview questions, however they were assured that their responses were anonymous and would not affect their employment. Lastly, we did not collect information on participants' smoking status or tobacco use history, which may have impacted their responses to questions regarding the implementation of a smoking cessation program.

\section{CONCLUSION}

Overall, this study provides a set of factors integrated community mental health administrators and leaders should consider when planning to implement a smoking cessation treatment in their organization targeted at clients with serious mental health diseases. When considering our findings, leaders of community health centers and mental health clinics may want to ensure that in addition to the smoking cessation services, the organization engages providers in education and training regarding the attitudes toward smoking cessation, meet more regularly with interdisciplinary team leaders to ensure all elements of the organizations incentive structures are aligned to support success of the program, and ensure that the organization is supporting team members commitment to such a service. 


\section{DECLARATIONS:}

Ethics approval and consent to participate

This study was approved by the State of Ohio IRB, study ID 2017 X0036.

\section{Consent for publication}

Informed consent was obtained prior to participation, and each participant received a \$20 Target store gift care for their participation in the study.

\section{Availability of data and materials}

The data analyzed during the current study are available from the corresponding authors on reasonable request.

\section{Competing interests}

The authors declare that they have no competing interests.

\section{Funding}

This work was funded through Ohio Department of Health, Grant/Award Number: CSP904017 01

\section{Author's contributions}

$\mathrm{TH}$, performed the design of the study, participated in the data collection, carried out the data analysis and drafted the manuscript. TH] participated in the data analyses and drafting the manuscript. AM, NB and AF participated in the design of the study, recruitment of participants, and redrafted the manuscript. All authors read and approved the final manuscript.

\section{Acknowledgements}

There are no acknowledgements 


\section{REFERENCES}

1. Prochaska JJ. Smoking and mental illness - Breaking the link. N Engl J Med. 2011;365(3):196-198. doi:10.1056/NEJMp1 105248

2. Callaghan RC, Veldhuizen S, Jeysingh T, et al. Patterns of tobacco-related mortality among individuals diagnosed with schizophrenia, bipolar disorder, or depression. J Psychiatr Res. 2014;48(1):102-110. doi:10.1016/J.JPSYCHIRES.2013.09.014

3. De Leon J, Diaz FJ. A meta-analysis of worldwide studies demonstrates an association between schizophrenia and tobacco smoking behaviors. Schizophr Res. 2005;76(2-3):135157. doi:10.1016/j.schres.2005.02.010

4. Dickerson F, Stallings CR, Origoni AE, et al. Cigarette smoking among persons with schizophrenia or bipolar disorder in routine clinical settings, 1999-2011. Psychiatr Serv. 2013;64(1):44-50. doi:10.1176/appi.ps.201200143

5. McClave AK, McKnight-Eily LR, Davis SP, Dube SR. Smoking characteristics of adults with selected lifetime mental illnesses: Results from the 2007 national health interview survey. Am J Public Health. 2010;100(12):2464-2472. doi:10.2105/AJPH.2009.188136

6. Ward B, Clarke T, Freeman G, Schiller J. Early Release of Selected Estimates Based on Data From the 2014 National Health Interview Survey.; 2015.

7. Adler LE, Olincy A, Waldo M, et al. Schizophrenia, sensory gating, and nicotinic receptors. Schizophr Bull. 1998;24(2):189-202.

doi:10.1093/oxfordjournals.schbul.a033320

8. Kumari V, Postma P. Nicotine use in schizophrenia: The self medication hypotheses. Neurosci Biobehav Rev. 2005;29(6):1021-1034. doi:10.1016/J.NEUBIOREV.2005.02.006

9. Leonard S, Adler LE, Benhammou K, et al. Smoking and mental illness. Pharmacol Biochem Behav. 2001;70(4):561-570. doi:10.1016/S0091-3057(01)00677-3

10. Tsoi DT, Porwal M, Webster AC. Interventions for smoking cessation and reduction in individuals with schizophrenia. Cochrane Database Syst Rev. 2013;(2). doi:10.1002/14651858.CD007253.pub3

11. Breitborde NJ, Dawson SC, Woolverton C, et al. A randomized controlled trial of cognitive remediation and d-cycloserine for individuals with bipolar disorder. BMC Psychol. 2014;2(1):41. doi:10.1186/s40359-014-0041-4

12. Breitborde NJK, Bell EK, Dawley D, et al. The Early Psychosis Intervention Center (EPICENTER): Development and six-month outcomes of an American first-episode psychosis clinical service. BMC Psychiatry. 2015;15(1):1-11. doi:10.1186/s12888-0150650-3

13. Breitborde NJK, Moe AM. Metacognitive Remediation: A Service Delivery Protocol. Phoeix, AZ; 2016.

14. Breitborde NJK, Woolverton C, Dawson SC, et al. Meta-cognitive skills training enhances computerized cognitive remediation outcomes among individuals with first-episode psychosis. Early Interv Psychiatry. 2017;11(3):244-249. doi:10.1111/eip.12289

15. Muilenburg JL, Laschober TC, Eby LT. Organizational Factors as Predictors of Tobacco Cessation Pharmacotherapy Adoption in Addiction Treatment Programs. J Addict Med. 2014;8(1):59-65. doi:10.1097/ADM.0000000000000008

16. Fuller BE, Guydish J, Tsoh J, et al. Attitudes toward the integration of smoking cessation treatment into drug abuse clinics. J Subst Abuse Treat. 2007;32(1):53-60.

doi:10.1016/j.jsat.2006.06.011 
17. Malte CA, McFall M, Chow B, Beckham JC, Carmody TP, Saxon AJ. Survey of providers' attitudes toward integrating smoking cessation treatment into posttraumatic stress disorder care. Psychol Addict Behav. 2013;27(1):249-255. doi:10.1037/a0028484

18. Wills TA, Knight R, Williams RJ, Pagano I, Sargent JD. Risk Factors for Exclusive ECigarette Use and Dual E-Cigarette Use and Tobacco Use in Adolescents. Pediatrics. 2015;135(2). doi:10.1542/peds.2014-0760

19. Rogers ES, Gillespie C, Smelson D, Sherman SE. A qualitative evaluation of mental health clinic staff perceptions of barriers and facilitators to treating tobacco use. Nicotine Tob Res. 2017;(July):1-8. doi:10.1093/ntr/ntx204

20. Croghan T, Brown J. Integrating Mental Health Treatment Into the Patient Centered Medical Home.; 2010.

21. Reynolds B, Penfold RB, Patak M. Dimensions of impulsive behavior in adolescents: Laboratory behavioral assessments. Exp Clin Psychopharmacol. 2008;16(2):124-131. doi:10.1037/1064-1297.16.2.124

22. The Panel of Clinical Practice Guideline Treating Tobacco Use and Dependence 2008. A Clinical Practice Guideline for Treating Tobacco Use and Dependence: U.S. 2008 Update.; 2008. doi:10.1016/j.amepre.2008.04.009

23. Palinkas LA, Horwitz SM, Green CA, Wisdom JP, Duan N, Hoagwood K. Purposeful Sampling for Qualitative Data Collection and Analysis in Mixed Method Implementation Research. Adm Policy Ment Heal Ment Heal Serv Res. 2015;42(5):533-544. doi:10.1007/s10488-013-0528-y

24. Creswell JW. Qualitative Inquiry \& Research Design: Choosing Among Five Approaches. Vol 2nd. Thousand Oaks, CA: SAGE Publications; 2013. doi:10.1111/1467-9299.00177

25. Lincoln YS, Buba EG. Naturalistic Inquiry. Newbury Park, CA: SAGE Publications

26. Zullino DF, Delessert D, Eap CB, Preisig M, Baumann P. Tobacco and cannabis smoking cessation can lead to intoxication with clozapine or olanzapine. Int Clin Psychopharmacol. 2002;17(3):141-143. doi:10.1097/00004850-200205000-00008

27. Brownson RC, Colditz GA, Proctor EK. Dissemination and Implementation Research in Health : Translating Science to Practice.

https://books.google.com/books?id=1cM9DwAAQBAJ\&dq=implementing+interventions + into + health + center\&lr $=$. Accessed September 17, 2019.

28. Silva P, Ferreira A. Performance management in primary healthcare services: evidence from a field study. Qual Res Account Manag. 2010;7(4):424-449. doi:10.1108/11766091011094527

29. Yeager VA, Menachemi N, Savage GT, Ginter PM, Sen BP, Beitsch LM. Using resource dependency theory to measure the environment in health care organizational studies. Health Care Manage Rev. 2014;39(1):50-65. doi:10.1097/HMR.0b013e3182826624

30. Blumenthal DS. Barriers to the provision of smoking cessation services reported by clinicians in underserved communities. J Am Board Fam Med. 2007;20(3):272-279. doi:10.3122/jabfm.2007.03.060115

31. Himelhoch S, Daumit G. To Whom Do Psychiatrists Offer Smoking-Cessation Counseling? Am J Psychiatry. 2003;160(12):2228-2230. doi:10.1176/appi.ajp.160.12.2228

32. Berwick DM. Disseminating Innovations in Health Care. JAMA. 2003;289(15):1969. doi:10.1001/jama.289.15.1969 
Table 1: Themes and sub-themes

\begin{tabular}{|c|c|c|}
\hline Theme & Description & Example quotation \\
\hline \multicolumn{3}{|c|}{ Environmental Level Factors } \\
\hline $\begin{array}{l}\text { Reimbursement } \\
\text { Mechanisms }\end{array}$ & $\begin{array}{l}\text { The organization's ability to } \\
\text { implement the program will } \\
\text { be based on whether they can } \\
\text { receive reimbursement for } \\
\text { MCR-Q. }\end{array}$ & $\begin{array}{l}\text { "It's difficult because [we're an] FQHC so } \\
\text { um you know HRSA really decides what } \\
\text { we do with our money." }\end{array}$ \\
\hline \multicolumn{3}{|c|}{ Organizational Level Factors } \\
\hline $\begin{array}{l}\text { Multi- } \\
\text { disciplinary } \\
\text { provider teams }\end{array}$ & $\begin{array}{l}\text { The organization has multi- } \\
\text { disciplinary teams (FQHC \& } \\
\text { Mental Health and Addiction } \\
\text { Services), which is conducive } \\
\text { to a smoking cessation } \\
\text { program which requires a } \\
\text { combination of medication } \\
\text { and therapy. }\end{array}$ & $\begin{array}{l}\text { "Okay. Well we already have a lot of } \\
\text { integration between the two sides. You } \\
\text { know they were behavioral health for a } \\
\text { long time and then they added primary } \\
\text { care later. Um, so probably things that we } \\
\text { have going first would be a good place to } \\
\text { do it, cause we have like a whole } \\
\text { integrated team that we have, approach } \\
\text { with our patients." }\end{array}$ \\
\hline $\begin{array}{l}\text { Aligning the } \\
\text { human } \\
\text { resource } \\
\text { incentive } \\
\text { program with } \\
\text { MCR-Q }\end{array}$ & $\begin{array}{l}\text { The organization utilizes } \\
\text { productivity hours to measure } \\
\text { staff productivity throughout } \\
\text { with the exception of the } \\
\text { primary care clinic and the } \\
\text { program would need to align } \\
\text { with this incentive structure. }\end{array}$ & $\begin{array}{l}\text { "I think XXXXX [Organization name] } \\
\text { would really have to say hey this is what } \\
\text { we're gonna do for you if you do this. } \\
\text { We're gonna give you this much } \\
\text { productivity for it. A lot of it depends on } \\
\text { the productivity that's gonna come out of } \\
\text { this for the people." }\end{array}$ \\
\hline \multicolumn{3}{|l|}{ Providers } \\
\hline $\begin{array}{l}\text { Workload } \\
\text { constraints }\end{array}$ & $\begin{array}{l}\text { Team members expressed a } \\
\text { lack of time or resources to } \\
\text { making smoking cessation a } \\
\text { priority. }\end{array}$ & $\begin{array}{l}\text { "I think you know, um, the challenge } \\
\text { would be the case workers saying, this is } \\
\text { one more thing I have to do. That would } \\
\text { be a big one." }\end{array}$ \\
\hline $\begin{array}{l}\text { Buy In of } \\
\text { providers/team } \\
\text { members }\end{array}$ & $\begin{array}{l}\text { Various team members have } \\
\text { different levels of buy in and } \\
\text { varying attitudes toward } \\
\text { adopting this new program. }\end{array}$ & $\begin{array}{l}\text { "Yeah. But with the therapists you know I } \\
\text { think most enjoy learning and trying out } \\
\text { new things so." }\end{array}$ \\
\hline $\begin{array}{l}\text { Provider } \\
\text { prescribing } \\
\text { behaviors }\end{array}$ & $\begin{array}{l}\text { Getting providers who } \\
\text { prescribe to change behaviors } \\
\text { to incorporate potential side } \\
\text { effects/interactions with } \\
\text { smoking cessation drugs. }\end{array}$ & $\begin{array}{l}\text { "Um but help them understand that when } \\
\text { they're prescribing if they have a client in } \\
\text { the smoking cessation program under } \\
\text { Bubenorphine to please be willing to } \\
\text { adjust the psychiatric meds as best able to } \\
\text { support the program." }\end{array}$ \\
\hline
\end{tabular}




\begin{tabular}{|c|c|c|}
\hline Patients & & \\
\hline $\begin{array}{l}\text { Motivation to } \\
\text { quit smoking }\end{array}$ & $\begin{array}{l}\text { Getting patients to be } \\
\text { motivated to have an intention } \\
\text { to quit. }\end{array}$ & $\begin{array}{l}\text { "So, I think it's - it'll be difficult to try to } \\
\text { get them to understand that they really } \\
\text { need, you know, to stop smoking." }\end{array}$ \\
\hline $\begin{array}{l}\text { Competing } \\
\text { patient social } \\
\text { needs and } \\
\text { priorities }\end{array}$ & $\begin{array}{l}\text { Due to complex social needs } \\
\text { (housing, transportation) of } \\
\text { the clients, smoking cessation } \\
\text { may not be feasible or the } \\
\text { most appropriate need to } \\
\text { address during clinic } \\
\text { interactions. }\end{array}$ & $\begin{array}{l}\text { "I've always said it's hard to stop drinking } \\
\text { when you're sleeping under a bridge it's } \\
\text { probably going to be hard to stop smoking } \\
\text { too." } \\
\text { "Just our population can be difficult and } \\
\text { you know just being mindful of that. Uh } \\
\text { they have a lot of barriers you know } \\
\text { whatever their trying to do. Um you know } \\
\text { a lot of our people are homeless who } \\
\text { come here." }\end{array}$ \\
\hline
\end{tabular}

